\title{
ESPACIALIZAÇÃO DA PRECIPITAÇÃO PLUVIAL MÉDIA TOTAL MENSAL E SAZONAL DA BACIA HIDROGRÁFICA DO ALTO JACUí/RS
}

\author{
Jakeline Baratto $^{(a)}$, Cássio Arthur Wollmann ${ }^{(b)}$ \\ (a) Doutoranda do Programa de pós-graduação em Geografia/Bacharel em Geografia, Licencianda em Geografia, \\ Universidade Federal de Santa Maria, jekeline.jake@ hotmail.com \\ (b) Professor do Programa de pós graduação em Geografia/Bacharel em Geográfia, Universidade Federal de Santa \\ Maria, cassio_geo@yahoo.com.br
}

Eixo: 3. Climtologia em diferentes níveis escalares: mudanças e variabilidades

\begin{abstract}
Resumo/
O objetivo da pesquisa é espacializar a pluviometria média total mensal e sazonal da bacia hidrográfica do Alto Jacuí no período de 31 anos. Foram selecionados 27 postos pluviométricos com uma série temporal de janeiro de 1980 a dezembro de 2010. Os dados pluviométricos foram transferidos para uma planilha do Programa Microsoft Office Excel $2013 \mathrm{com}$ a finalidade de obter as médias das precipitações pluviométricas para o período mensal, sazonal entre todos os postos. Foi utilizado o método de Sturges para determinar o número de classes, sendo estabelecidas diferentes classe para os dois períodos, sendo utilizado para a espacialização da distribuição pluviométrica o programa Software ArcGIS 10.1. Dessa forma, foi possivel considerar que existe uma grande variação na distribuição espacial das chuvas em função da orografia na bacia hidrográfica. Com isso, a uma tendência na porção central e sudoeste a ter os menores valores.
\end{abstract}

Palavras chave: Variabilidade pluviométrica, orografia, bacia hidrográfica.

\section{Introdução}

A precipitação pluvial é um dos elementos climáticos que possui maior impacto no espaço geográfico, pois está relacionada com diversos setores da sociedade como a agricultura, recarga dos aquíferos, abastecimento humano e criação de animais. Contudo, para Galvani e Lima (2012), além da distribuição regional da precipitação pluviométrica, deve-se ser considerada a distribuição temporal, pois o planejamento de atividades agrícolas e econômicas de determinada região pode depender em função da distribuição sazonal das chuvas.

Nesse sentido, a chuva torna-se um elemento importante na compreensão do clima em escala regional e que pode ser considerado como um dos principais elementos na análise e organização para o planejamento territorial e ambiental. Segundo Rossato (2011), conhecer a caracterização da variabilidade anual das chuvas se torna importante pois fornece um panorama geral da distribuição da precipitação, destacando anos que se apresentam muito chuvosos ou muitos secos no conjunto de estações meteorológicas. 
O conhecimento da distribuição espacial pluviométrica constitui-se fator preponderante na tomada de medidas de governança referentes à relação disponibilidade - demanda de recursos hídricos, principalmente no que tange às esferas locais ou regionais (ZANDONADI; PASCOALINO, 2012).

Para Dziubate (2013), o conhecimento espaço-temporal da variabilidade das chuvas em uma bacia hidrográfica permite a disponibilidade de dados tanto para zoneamento agrícola, quanto para o abastecimento, contribuindo assim para a mitigação de impactos ambientais. Ainda, o autor coloca que o conhecimento da distribuição espacial e temporal das chuvas em uma bacia hidrográfica é de extrema importância pois permite o planejamento em períodos considerados críticos em caso de estiagem.

No Rio Grande do Sul, segundo Sartori (2003), as distribuições têmporo-espaciais das chuvas refletem-se por três condicionantes: a posição subtropical, a direção dos compartimentos de relevo e a direção geral dos deslocamentos das Frentes Polares, que é de sudoeste para nordeste. No Estado, segundo a referida, ocorre o aumento dos índices pluviométricos do quadrante sul para o quadrante norte conforme a disposição dos compartimentos geomorfológicos do Rio Grande do Sul, tendo as maiores altitudes ao norte e nordeste e menores altitudes a leste e sudeste.

Outro importante fator destacado pela autora, quando tratado sobre a distribuição têmporo-espacial, é o efeito orográfico, produzido pela barreira imposta da serra geral, que possuiu uma orientação de leste para oeste intensificando o processo de ascendência da dinâmica frontal. Sendo que as maiores precipitações do estado ocorrem na região nordeste do estado.

Além dos fatores geográficos na variação espacial da precipitação pluviométrica, o Rio Grande do Sul sofre na variação temporal a influência dos fenômenos La Niña e El Niño. Para o estado, conforme Berlato e Fontana (2003), um dos efeitos associados ao fenômeno El Niño é precipitação pluvial abundante, principalmente na primavera do ano de início do fenômeno e as precipitações ficam acima do normal no final do outono e no início do inverno do ano seguinte. Em relação às Frentes Frias, para o período de El Niño, elas podem ficar semi-estacionárias por vários dias, provocando precipitação pluvial. No período de La Niña as chuvas tende a diminuir principalmente na primavera e no início do verão, devido às rápidas passagens das Frentes Frias.

A análise da distribuição da precipitação pluviométrica em uma bacia hidrográfica possibilita compreender a dinâmica hidroclimática da mesma, auxiliando na identificação dos períodos mais chuvosos, e suas relações com o espaço geográfico. Portanto, conhecer essa dinâmica pluvial é de suma importância para a solução de problemas referentes aos períodos chuvosos e menos chuvosos, bem como, evitar os problemas referentes aos eventos extremos de precipitação, que resultam na entrada de sedimentos nos reservatórios, diminuindo sua vida útil. 


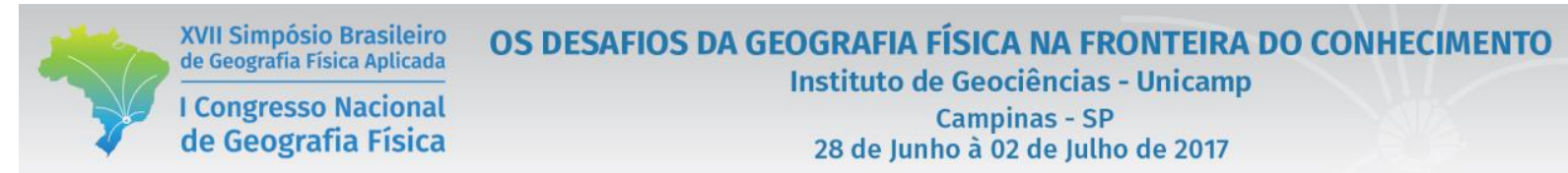

Nesse contexto, o objetivo da presente pesquisa é espacializar a pluviometria média total mensal e sazonal da bacia hidrográfica do Alto Jacuí no período de 31 anos. A bacia hidrográfica do Alto Jacuí foi selecionada como área de estudo do projeto Programa Nacional de Cooperação Acadêmica (PROCAD), cujo um dos objetivos é estabelecer metodologias a partir de técnicas de climatologia para análise em bacias hidrográficas, buscando avaliar as modificações ocorridas no meio ambiente a partir dos processos antrópicos de uso e ocupação.

\section{Materiais e métodos}

A bacia hidrográfica do Alto Jacuí está localizada na Região Hidrográfica do Guaíba, abrange uma área de $12.985,44 \mathrm{~km}^{2}$ (Figura 1). A área de estudo possui grande variação altimétrica, correspondendo de $85 \mathrm{~m}$ a 776 m acima do nível do mar.

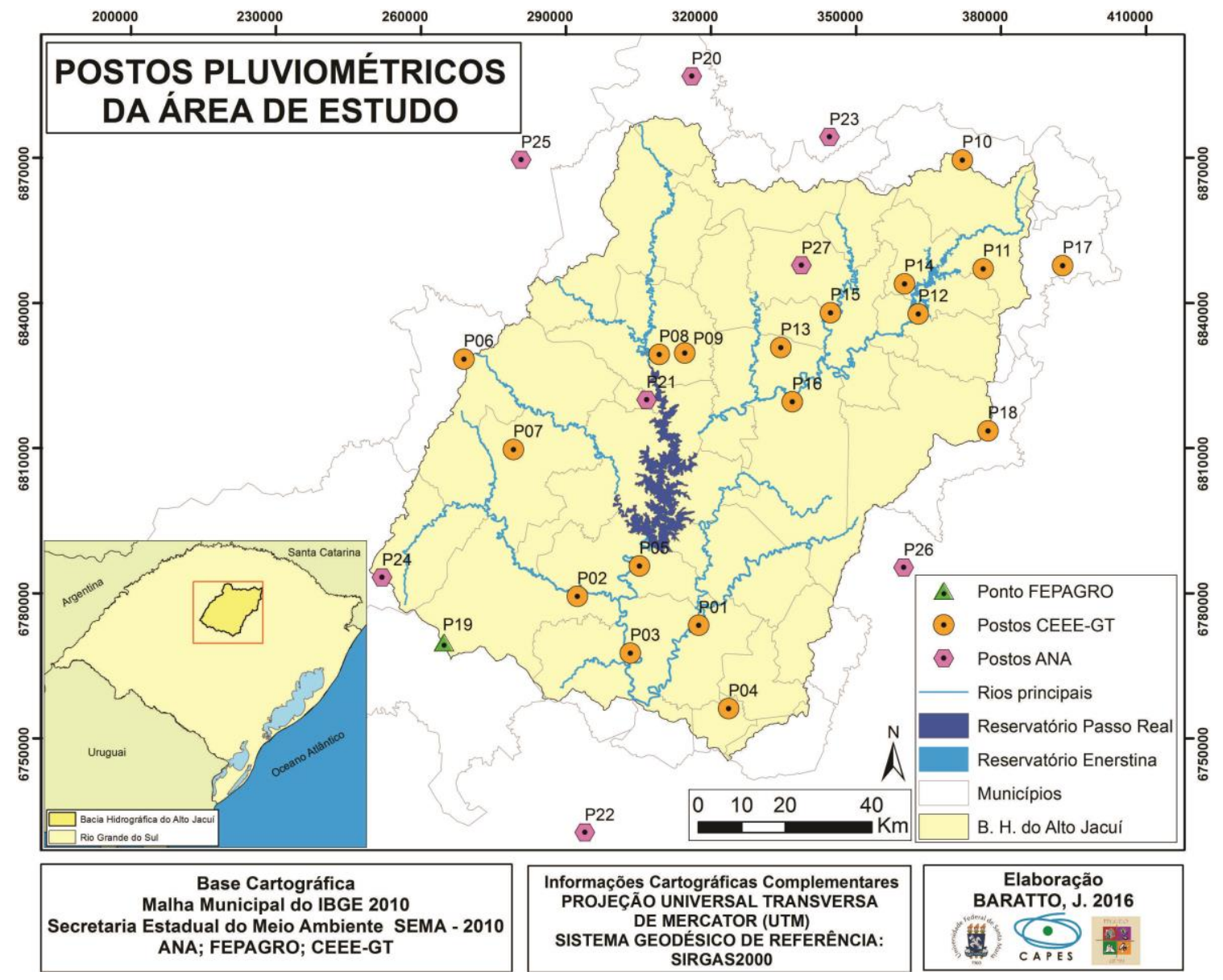

Figura 1 - Localização da área de estudo e dos postos pluviométricos 
Os dados de precipitação pluviométrica foram adquiridos por meio da Companhia Estadual de Energia Elétrica Geração e Transmissão (CEEE-GT) e da Agência Nacional das Águas (ANA), também foram utilizados dados pluviométricos da estação meteorológica da Fundação Estadual de Pesquisa Agropecuária (Fepagro). A escolhas dos postos pluviométricos se estabeleceu com base nos critérios estabelecidos por Chierice e Landim (2014), sendo eles: continuidade das informações nas bases de dados pluviométricos e nos anos; abrangência da bacia hidrográfica de interesse. A partir destes dados, foram selecionados 27 postos pluviométricos com uma série temporal de 31 anos, de janeiro de 1980 a dezembro de 2010. Para o preenchimento das falhas da série histórica da bacia hidrográfica do Alto Jacuí, foi utilizado a técnica do dado real do posto vizinho de menor distância, sendo também utilizado por Zandonadi e Pascoalino (2012).

Os dados foram transferidos para uma planilha do Programa Microsoft Office Excel 2013. No referido programa foram obtidas as médias das precipitações pluviométricas para o período mensal, sazonal entre todos os postos pluviométricos no período de 31 anos. Para representar as estações do ano foram utilizados os meses de dezembro, janeiro e fevereiro como o verão. Março, abril e maio como os meses de outono, e junho, julho e agosto como referente os meses de inverno, conforme sugere Wollmann (2011). Para a espacialização da distribuição pluviométrica da bacia hidrográfica do Alto Jacuí foram organizadas no Microsoft Office Excel 2013 tabelas referentes a precipitação pluviométrica média mensal, média sazonal da precipitação que posteriormente seriam importadas ao Software ArcGIS 10.1.

Antes de importá-las para o referido software foi necessário determinar o número de classes que cada cartograma. Assim, foi utilizado o método de Sturges para determinar o número de classes, sendo estabelecidas diferentes classe para cada cartograma. Em relação a precipitação pluviométrica mensal foram estabelecidas nove classes com intervalos iguais de $14 \mathrm{~mm}$ entre elas, sendo que as classes variam de 94 - 108 mm; 109 - 123 mm; 124 - 138 mm; 139 - 153 mm; 154 - 168 mm; 169 - 183 mm; 184 -198 $\mathrm{mm} ; 199$ - $213 \mathrm{~mm} ; 214$ - $228 \mathrm{~mm}$.

Para a precipitação média sazonal foram estabelecidos pelo método de Sturges oito classes com intervalos de classes iguais de $28 \mathrm{~mm}$, sendo que os intervalos variam ente 377 - $395 \mathrm{~mm}$; 396 - $425 \mathrm{~mm}$; 426 - 454 mm; 484 - $521 \mathrm{~mm} ; 522$ - $541 \mathrm{~mm} ; 542$ - $570 \mathrm{~mm} ; 571$ - $599 \mathrm{~mm}$. Para a precipitação média anual foram estabelecidas seis classes com intervalos iguais de $55 \mathrm{~mm}$, sendo as classes de 1637 - $1691 \mathrm{~mm}$; 1692 1747 mm; 1748 - 1803mm; 1804 - 1859 mm; 1560 - 1915 mm; 1916 - 1971 mm. Em relação a precipitação pluviométrica total anual foram estabelecidas onze classes com intervalos iguais de $188 \mathrm{~mm}$ sendo elas, 888 - 1076 mm; 1077 - 1265 mm; 1266 - 1454 mm; 1455 - 1643 mm; 1644 - 1832 mm; 1833 2021 mm; 2022 - 2210 mm; 2211 - 2399 mm; 2400 - 2588 mm; 2589 - 2777mm; 2778 - 2966 mm. 
Através do programa computacional (ArcGIS 10.1), foram geradas as isoietas pelo método de interpolação geoestatística krigagem ordinária, cujo modelo de semiovariograma utilizado foi o esférico, pois segundo Wollmann (2011) a krigagem ordinária é um método muito utilizado para a espacialização de dados climáticos. Após gerar as isoietas referente a cada mapa os mesmos foram organizados em cartogramas para melhor análise dos dados. Com isso, foram gerados 4 cartogramas, sendo cada um referente a um período sazonal e os meses referentes a eles.

\section{Ressultados e Discuções}

Nos meses referentes ao período do verão (dezembro, janeiro e fevereiro) a precipitação pluviométrica média para os 31 anos em análise foi de 427,6mm como salientado anteriormente. No mês de dezembro o posto que teve a menor precipitação pluviométrica media sendo o posto 09 , com $108,1 \mathrm{~mm}$ e que está localizado no município de Ibirubá Com relação ao posto de maior média mensal foi o posto 25 , com 169,8 mm que está localizado no município de Condor situado a noroeste da bacia. Na espacialização dos dados mensais de dezembro o setor norte da bacia obteve os maiores valores de precipitação pluviométrica variando entre $154-168 \mathrm{~mm}$. Na porção central e sul tiveram os menores valores da média mensal, sendo elas estabelecidas entre as cotas de 109-123mm. Assim, para o mês de dezembro a precipitação pluviométrica se distribui de sudoeste para nordeste dentro da bacia.

Para o mês de janeiro as médias máxima e mínima para o período foram nos postos 22 e o 21 com 171,1 mm e 144,8 mm, respectivamente. O primeiro posto está localizado no município de Quinze de Novembro, na porção central da bacia, enquanto que o segundo no município de Dona Francisca, situado na porção sul. Através da interpolação das médias mensais de todos os postos observou-se que ocorre uma homogeneidade nos dados de precipitação, assim, as distribuições de chuvas variaram entre $169-183 \mathrm{~mm}$. No mês de fevereiro o posto 21 manteve-se como menor média mensal sendo de $114,7 \mathrm{~mm}$, enquanto que o de maior média foi o 17 com uma precipitação de $159,1 \mathrm{~mm}$ o qual está localizado no município de Marau. Neste mês os setores norte e sudoeste da bacia tiveram as maiores precipitações médias variando entre $154-168 \mathrm{~mm}$. Na porção central da bacia concentrou-se uma ilhota de menor precipitação variando de $109-123 \mathrm{~mm}$.

Assim, para o período considerado de verão o posto 21 foi o que teve a menor média sazonal, com uma precipitação de 379,6 mm, localizado na porção central da bacia. Já o posto que obteve a maior média foi o 25 que está situado no município de Condor. Em relação a distribuição da precipitação pluviométrica, pequenas áreas da porção norte da bacia tiveram as maiores médias. Na porção central da bacia localizam- 


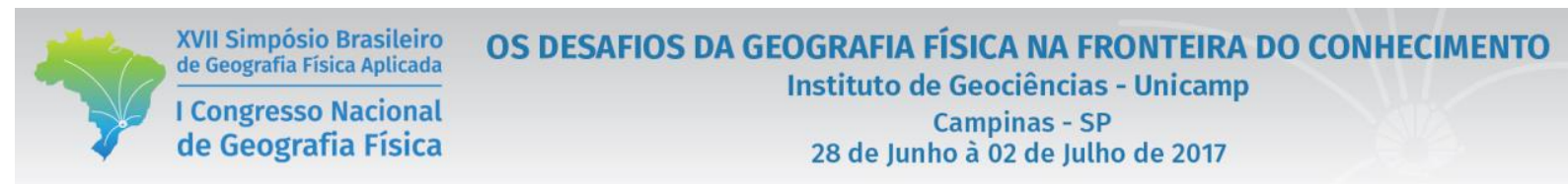

se os menores valores de precipitação média sazonal variando entre 377-395 mm. Na figura 2, é possível observar a espacialização da precipitação média mensal e sazonal do período do verão.

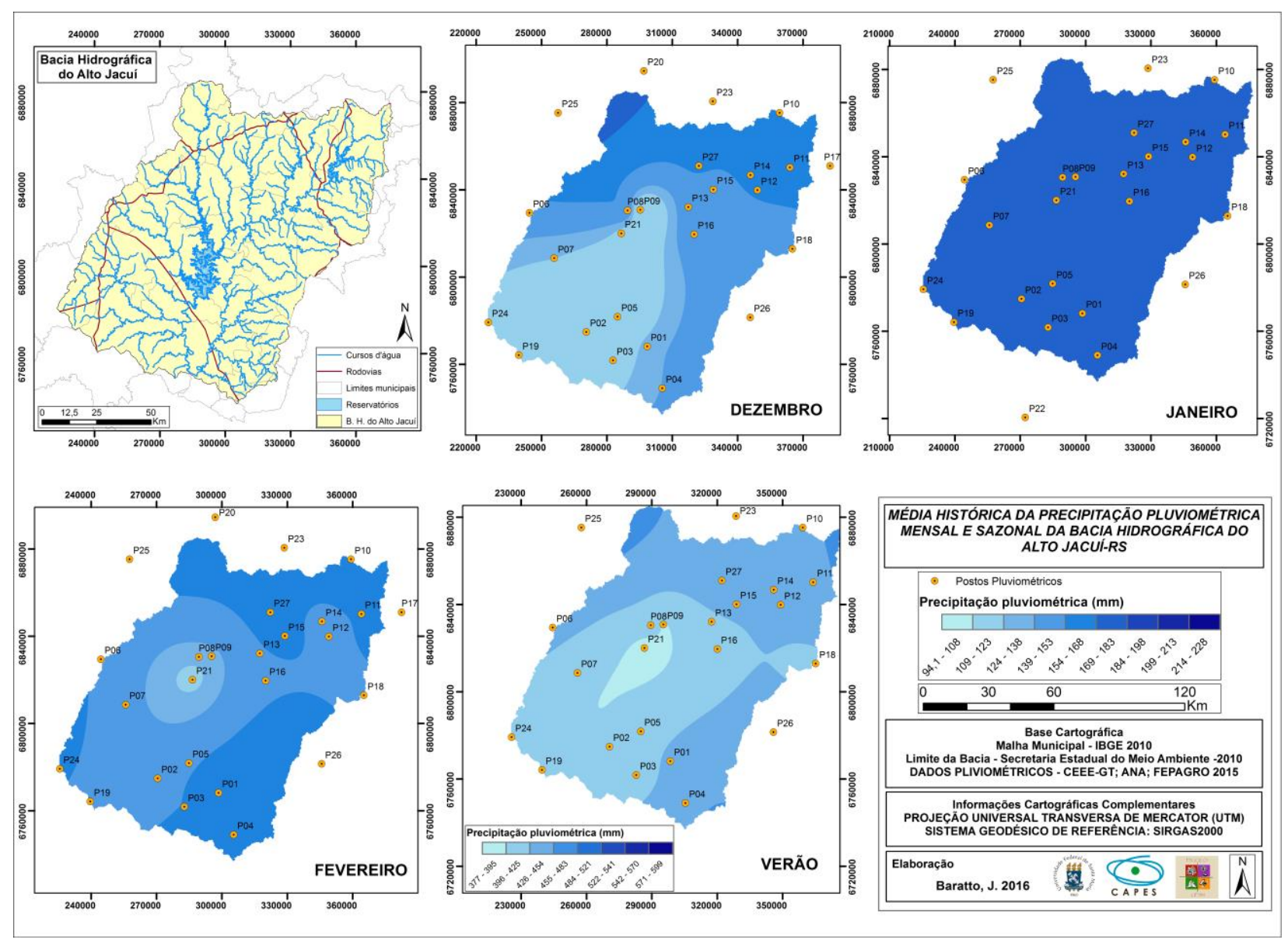

Figura 2 - Distribuição da precipitação pluviométrica no período do verão

.De maneira geral, no verão os menores valores de precipitação média se encontram na porção central próximo ao reservatório Passo Real, dados estes apresentados na figura 34, é possível observar a distribuição mensal e sazonal da precipitação média histórica do período do verão para a bacia hidrográfica do Alto Jacuí.

No período sazonal do outono os meses representativos são março, abril e maio, os quais apresentaram uma precipitação média sazonal de $407,1 \mathrm{~mm}$. No primeiro mês, março, o posto 17 teve a menor precipitação pluviométrica mensal $(94,3 \mathrm{~mm})$ que está localizado no município de Marau, já o posto 22 localizado em Dona Francisca foi o que teve a maior média mensal, com 137,9mm. Na variação espacial da precipitação o mês de março teve os menores valores de precipitação média no setor central e nordeste 


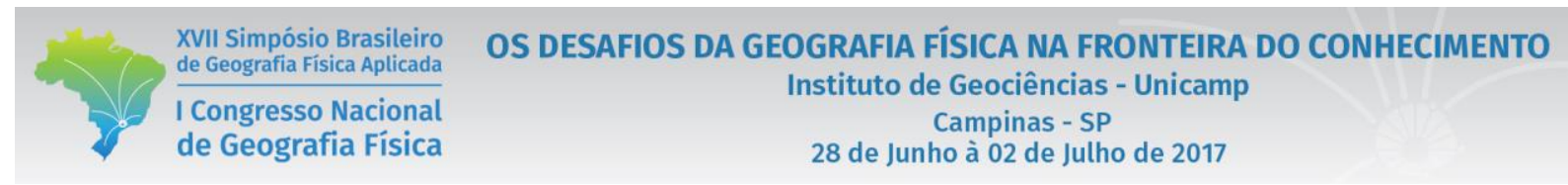

da bacia, sendo que os valores variam entre 94,1-108mm, nas outras áreas da mesma os valores de precipitação variam entre 109-123mm.

No mês de abril o posto 12 foi o que teve a menor precipitação média $(135,0 \mathrm{~mm})$ este localizado no município de Passo Fundo. O posto 04, localizado em Arroio do Tigre na porção sul da bacia, obteve a maior média com $1774,9 \mathrm{~mm}$, na interpolação dos dados de precipitação média para o mês em análise, o setor oeste e sul alcançou os maiores valores, os quais variam entre 184-198mm, enquanto que a porção central e nordeste tiveram os menores valores de precipitação média mensal, com variação de 169$183 \mathrm{~mm}$. Na figura 3, é possível observar a espacialização da precipitação média mensal e sazonal do período do verão

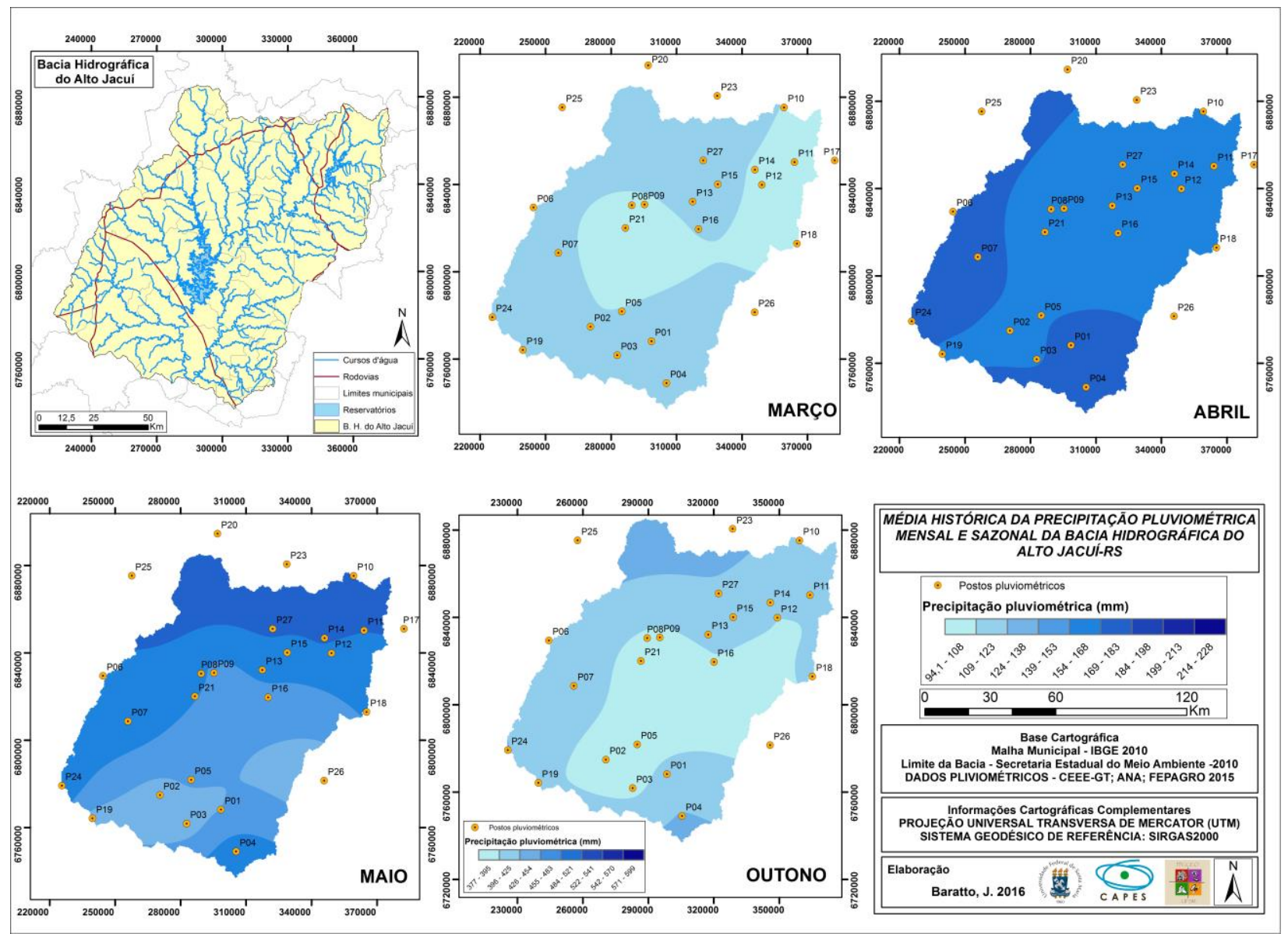

Figura 3 - Distribuição da precipitação pluviométrica no período do outono

Para maio o posto 26 foi o que atingiu a menor média para o período com 120,9 mm estando localizado no município de Barros Cassal. O posto 25 foi o que obteve a maior média, sendo este localizado no 
município de Condor. Em maio, o setor norte da bacia obteve os maiores valores de precipitação variando de 154-168mm. Na porção sudoeste da bacia e em uma pequena área na porção leste contiveram as menores precipitações para o mês, com variação de 109-123mm, neste mês ocorreu um aumento da precipitação de sul para norte.

No período sazonal do outono o posto 03 (Figura 35), foi o que atingiu a menor precipitação média, com $366,9 \mathrm{~mm}$, e está localizado no município de Arroio do Tigre. O posto 22, localizado no município de Dona Francisca, alcançou a maior precipitação para o período com 460,5mm. Relacionada a distribuição espacial das chuvas, para o outono os maiores volumes concentraram-se no setor norte da bacia, assim o volume precipitado nessa área varia entre $426-454 \mathrm{~mm}$. Já na porção centro-leste da bacia, tiveram os menores valores de precipitação com variação de 377-395mm. Os menores volumes de chuva foram próximos ao reservatório Passa Real e nas maiores altitudes da bacia, bem como analisado nos meses do período sazonal do verão.

No período do inverno, cujo os meses referentes são junho, julho e agosto, a precipitação média sazonal foi de $430,6 \mathrm{~mm}$. Para o mês de junho o posto 02 foi o que atingiu a menor média pluviométrica, com 126,3 mm sendo localizado no município de Júlio de Castilhos. O posto 24 alcançou a maior média para o mês de junho com 161,7mm, estando localizado no município de Tupanciretã. Neste mês com a interpolação dos dados pluviométricos não foi possível observar grande variação, assim a precipitação pluviométrica dentro de todos os postos ficou no intervalo de $154-168 \mathrm{~mm}$.

O segundo mês referente ao período do inverno, julho (figura 4), o posto 09 atingiu a menor média mensal com 144,9mm. Já o posto 26 obteve-se a maior média com 187,0mm localizado no município de Barros Cassal. No mês de julho a porção central da bacia atingiu os menores valores de precipitação, com variação de 154-168mm. Os maiores valores de precipitação média sazonal ocorreram na porção sudeste da bacia, com variação de $184-198 \mathrm{~mm}$. As outras áreas da bacia tiveram a precipitação entre $169-183 \mathrm{~mm}$. No mês de agosto o posto 03 foi o que atingiu a menor média com 105,1 mm, que está localizado no município de Arroio do Tigre. O posto 26 obteve-se a maior precipitação média com 143,0mm. Neste mês pode-se observar que ocorreu grande variação da precipitação média na bacia. Na porção sul e sudoeste localizando as menores variações da precipitação, variando entre $109-123 \mathrm{~mm}$. Na porção central da bacia foi possível observar uma ilhota com precipitação média baixa. Os maiores valores de precipitação média estão localizados nos setores nordeste e leste, com variação de 139-153mm. Assim, foi possível verificar que a precipitação média mensal para a bacia no mês de agosto variou de sudoeste para nordeste, sendo que em sudoeste ocorreram os menores valores e a nordeste com os maiores valores de precipitação. No inverno o posto 26 foi o que alcançou a maior precipitação média, com 478,0mm que está localizado no município de Barros Cassal, bem como no mês anterior. O posto 09 obteve a menor média para o 


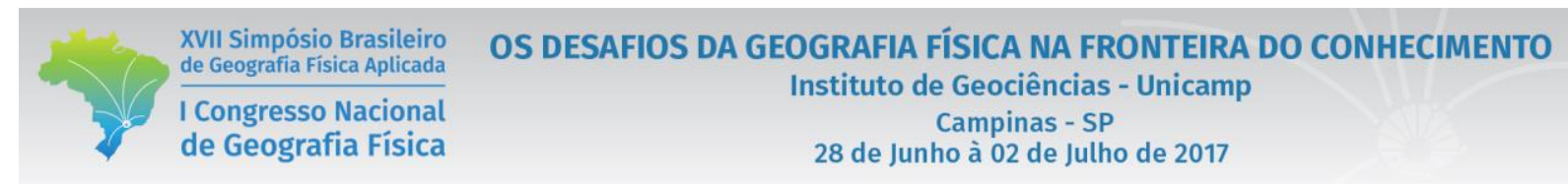

inverno, com 388,1mm que está localizado no município de Ibirubá Na variação espacial dos dados da precipitação pluviométrica sazonal os menores valores de precipitação se localizam na porção central da bacia, cuja variação é de 396-425 mm. Na porção leste e oeste da bacia tiveram os maiores valores de chuva para o período do inverno, sendo a variação de 455-483mm. Dessa forma, na bacia hidrográfica para o período do inverno, as menores precipitações ocorreram na porção central e as maiores próximo aos divisores de água da mesma.

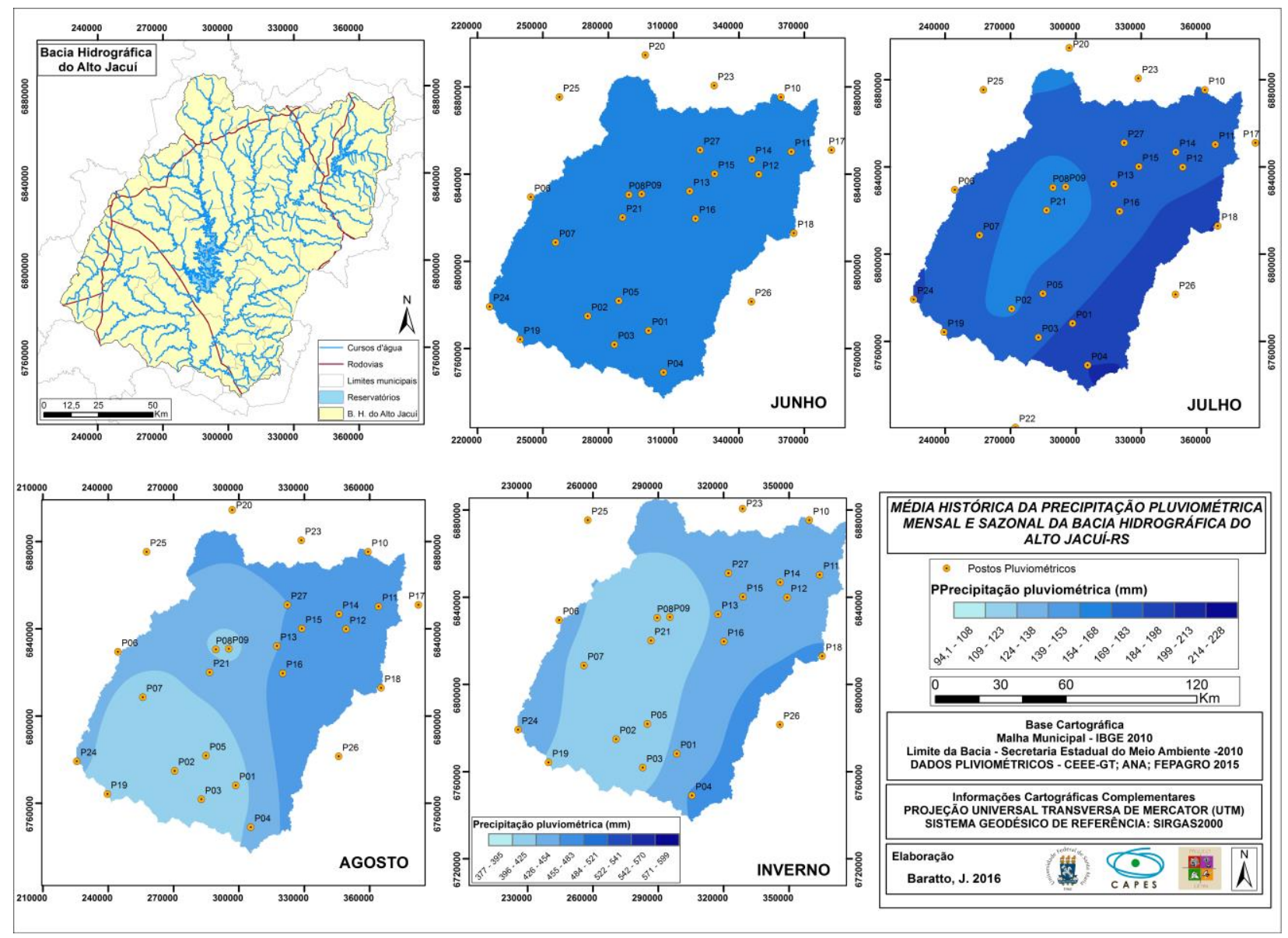

Figura 4 - Distribuição da precipitação pluviométrica no período do inverno

No período sazonal da primavera que corresponde os meses de setembro, outubro e novembro, foi o período sazonal mais chuvoso. Assim, a precipitação pluviométrica média foi de $533,9 \mathrm{~mm}$. No mês de setembro, o posto 02 obteve a menor precipitação média com 152, 5mm que está localizado no município de Júlio de Castilhos. O posto 25 atingiu a maior média mensal com 198,6mm localizado no município de Condor. Na porção norte da bacia ocorreram os maiores valores de precipitação média mensal, variando entre $190-228 \mathrm{~mm}$. Na porção sudoeste da bacia ocorreram os menores 


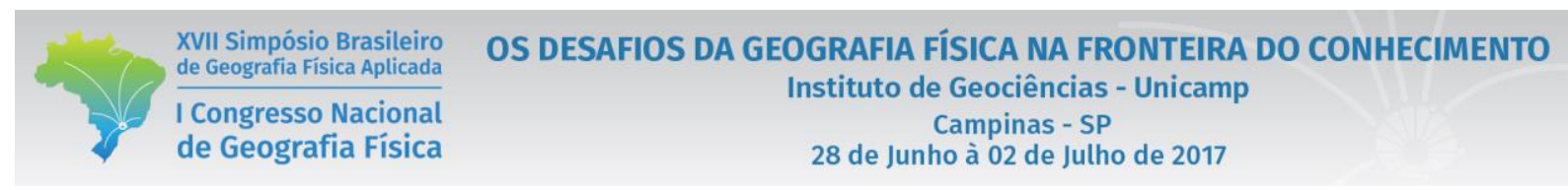

valores de precipitação mensal, variando entre 154-168mm. As distribuições das chuvas para a bacia no mês de setembro ocorreram de sudoeste para norte, sendo as menores médias localizadas na porção sudoeste e as maiores no norte da mesma.

Na figura 5, é possível ver a distribuição da precipitação pluviométrica nos meses de primavera.

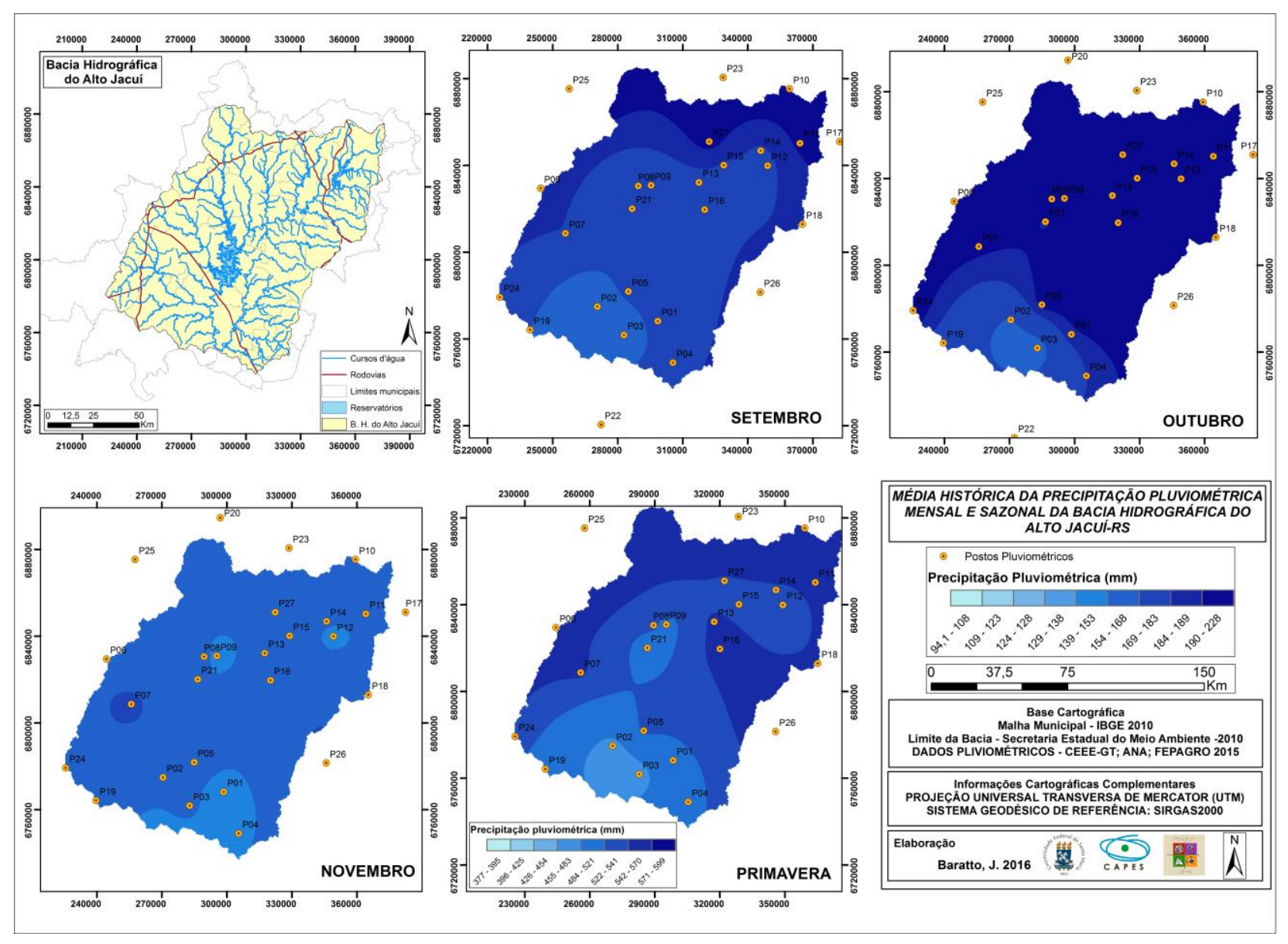

Figura 5 - Distribuição da precipitação pluviométrica no período da primavera

Para o mês de outubro o posto 03 obteve a menor precipitação média, com 161,9mm, localizado no município de Arroio do Tigre. O posto de maior média mensal continuou sendo o 25 com 223,3mm. $\mathrm{Na}$ espacialização das médias mensais de outubro pode-se perceber que a maior parte da bacia hidrográfica possui uma variação entre $190-228 \mathrm{~mm}$. Na porção sudoeste ocorreram os menores valores de precipitação pluviométrica que variaram entre $154-168 \mathrm{~mm}$.

Em novembro o posto 25 continuou sendo o posto de maior média mensal com 172,6mm. Já o posto com menor média foi o 22 com uma precipitação de $145,8 \mathrm{~mm}$. Na espacialização dos dados do mês 
de novembro a maior parte da bacia obteve uma precipitação média mensal entre $154-168 \mathrm{~mm}$. Na porção sul da bacia os valores de precipitação média variaram entre 139-153mm. Também pode-se observar algumas ilhotas com precipitação média mensal de 139-153mm. Nas proximidades ao ponto 07 a precipitação média mensal variou entre $169-183 \mathrm{~mm}$.

O período sazonal da primavera o posto que obteve a menor média foi o posto 3 com 472,1mm que está localizado no município de Arroio do Tigre. O posto que atingiu a maior precipitação média foi o posto 25 com $594,4 \mathrm{~mm}$. A porção sudoeste da bacia ocorreram os menores valores de precipitação média sazonal, variando entre 455-483mm. Também foi possível constatar que na porção central, próxima aos pontos P21, P08 e P09, uma ilhota com precipitação média sazonal de 484-521mm. Os maiores valores totais da precipitação se localiza no setor oeste, norte e leste da bacia hidrográfica, com precipitação de 542-570mm. Assim, os maiores volumes de chuvas, para a área de estudo na primavera, predominam na porção norte da bacia. Na porção sudoeste e sul concentram-se os menores valores de precipitação.

\section{Conclusão}

Em relação aos períodos mensais pode-se observar que embora não haja uma similaridade nas distribuições das chuvas, a maioria dos meses apresentaram na sua porção sul e sudoeste os menores valores de precipitação média mensal, enquanto que na porção norte e nordeste os maiores valores, como por exemplo, em dezembro, maio, agosto setembro, outubro.

Dois meses (janeiro e junho) tiveram a precipitação média semelhante para todos os postos pluviométricos, seguido pelos meses de março e abril, os quais se comportaram da mesma forma, sendo que no centro-norte alcançaram as menores médias. O mês de abril obteve as médias maiores. Os meses de fevereiro, julho, novembro tiveram comportamentos diferentes da distribuição da precipitação em relação dos demais meses. Em fevereiro a poção central da bacia obteve as menores médias. O mês de julho atingiu uma precipitação média semelhante ao mês de fevereiro. Em novembro ocorreram ilhotas de maior e menores média. Nos períodos sazonais a porção central da bacia obteve as menores médias. Na primavera e no outono a porção norte alcançou as maiores médias de precipitação pluvial. Já no inverno a porção leste e sudoeste obteve as maiores médias.

Com isso, é possível considerar que existe uma grande variação na distribuição espacial das chuvas em função da orografia na bacia hidrográfica do Alto Jacuí. Assim, a bacia contém uma grande variação hipsométrica ao longo da sua extensão fazendo-se que haja esta grande variação na distribuição espacial 


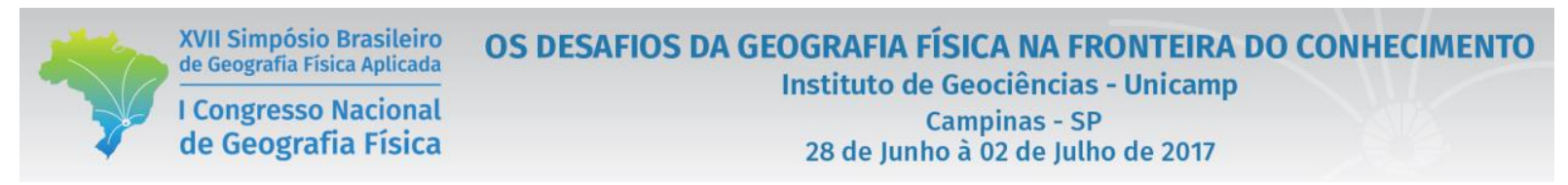

das chuvas. Dessa forma, é compreensível considerar que o efeito orográfico é um fator importantíssimo na variação pluviométrica. Porém, há uma tendência na porção central e sudoeste a ter os menores valores. O fator de maior impacto deste trabalho está direcionado no auxílio do planejamento dos recursos hídricos da bacia hidrográfica do Alto Jacuí. Afinal, conhecer a dinâmica pluviométrica deste local permite maior propriedade ao se desenvolver projetos de desenvolvimento para a região de influência. Trazendo com isso a melhor utilização do potencial energético e hídrico da bacia, com base nos fatores de qualidade e a sustentabilidade dos recursos hídricos do objeto de estudo.

\section{Bibliografia}

AYOADE, J. O. Introdução a Climatologia para os Trópicos. 10. ed. Rio de Janeiro: Bertrand Brasil, 2002.

BERLATO, M.A.; FONTANA, D.C. El Niño e La Niña: impactos no clima, na vegetação e na agricultura do Rio Grande do Sul; aplicações de previsões climáticas na agricultura. Porto Alegre: UFRGS, 2003.

CHIERICE, R. A. F. \& LANDIM, P. M. B. Variabilidade Espacial e Temporal de Precipitação Pluviométrica na Bacia Hidrográfica do Rio Mogi Guaçu. São Paulo, UNESP, Geociências, v. 33, n. 1, p.157-171, 2014. Disponível em: <http://www.revistageociencias.com.br/33/volume33_1_files/33-1-artigo-12.pdf>. Acesso em: 15 de Abr. 2015.

CORREA, M. G. G. Distribuição espacial e variabilidade da precipitação pluviométrica na bacia do rio Piquiri-PR. Dissertação (Mestre em Geografia Física) -Faculdade de Filosofia, Letras e Ciências Humanas da Universidade de São Paulo, São Paulo, 2013.

DZIUBATE, E.R. Análise da distribuição espacial e temporal da pluviosidade na bacia do rio Pirapó-PR. 2013. 71, p. Trabalho de Conclusão de Curso (Graduação em Engenharia Ambiental) - Universidade Tecnológica Federal do Paraná. 2013

GALVANI, E. (Org.); LIMA, N. G. B. de (Org.). Climatologia Aplicada: Resgate aos estudos caso. 1. ed. Curitiba: Editora CRV, 2012. v. 1. 192 p.

MACHADO, F.P. Contribuição ao estudo do clima do Rio Grande do Sul. IBGE, Rio de Janeiro, 1950.

ROSSATO. M. S. Os climas do Rio Grande do Sul: variabilidade, tendências e tipologia. 2011. 253 f. Tese (Doutorado em Geografia) - Universidade Federal do Rio Grande do Sul, Porto Alegre, 2011.

SARTORI, M. da G. B. A dinâmica do clima no Rio Grande do Sul: indução empírica e conhecimentos científicos. Terra Livre, São Paulo, Ano 19, vol. I, n. 20, p. 27-49,jan./jul. 2003.

SILVEIRA, P. da C. Precipitação pluviométrica na Bacia Hidrográfica do Rio Vacacaí, RS. 2012. 56 f. Dissertação (Mestrado em Geográfica) - Universidade Federal de Santa Maria, Santa Maria, 2012.

ZANDONADI, L.; PASCOALINO, A. Distribuição temporo-espacial das chuvas nas bacias dos rios Piracicaba, capivari e jundiaí (PCJ). REVISTA GEONORTE, Edição Especial, V.2, N.4, p.830 - 843, 2012.

WOLlmann, C. A. Zoneamento Agroclimático para a Produção de Roseiras (Rosaceae spp.) no Rio Grande do Sul. Tese (Doutorado em Geografia Física). Universidade de São Paulo. 2011. 382p. 2. V 